\title{
Epidemiology of HIV Among Injecting and Non-injecting Drug Users: Current Trends and Implications for Interventions
}

\author{
Steffanie A. Strathdee • Jamila K. Stockman
}

Published online: 11 April 2010

(C) The Author(s) 2010. This article is published with open access at Springerlink.com

\begin{abstract}
Injecting drug use is a major driver of HIV infections in Eastern Europe, the Commonwealth of Independent States, North Africa, the Middle East, and many parts of Asia and North America. We provide a global overview of the epidemiology of HIV infection among drug users and present current drug use trends that may constitute important epidemic drivers. We describe trends in ethnic disparities among injecting drug using (IDU) populations in the United States, and comment upon how these trends may now be changing. We present examples where HIV infection among non-IDUs who use cocaine, crack, and methamphetamine by other routes of administration is similar to that among IDUs, and discuss potential mechanisms of HIV spread in this overlooked population. Finally, we comment upon the potential implications of these observations for HIV interventions among IDU and non-IDU populations, taking into account different strategies that are needed in settings where HIV and/or injecting drug use has been established, or threatens to emerge.
\end{abstract}

Keywords HIV · AIDS · Injection drug use · Sub-Saharan Africa $\cdot$ Needle exchange programs $\cdot$ Opioid substitution treatment - Antiretroviral treatment $\cdot$ Prevention .

Epidemiology $\cdot$ Ethnicity $\cdot$ Interventions

\section{Introduction}

Drug dependence is a complex, chronic, relapsing condition that is often accompanied by severe health, psychological,

S. A. Strathdee $(\bowtie) \cdot$ J. K. Stockman

Division of Global Public Health, Department of Medicine,

University of California San Diego,

9500 Gilman Drive, MC 0507,

La Jolla, CA 92093-0507, USA

e-mail: sstrathdee@ucsd.edu economic, legal, and social consequences. Injecting drug users (IDUs) are particularly vulnerable to HIV and other blood-borne pathogens as a result of sharing contaminated syringes and other injecting equipment (e.g., cookers, cotton, and rinse water). Injecting drug use accounts for approximately $10 \%$ of HIV infections globally, but this proportion rises to $30 \%$ outside of Africa [1•]. Injecting drug use is the primary mode of HIV transmission in many countries throughout Eastern Europe, the Commonwealth of Independent States, North Africa, North America, the Middle East, and many parts of Asia [1•]. However, unprotected sex is also an important risk factor for HIV infection among IDUs, especially among women and men having sex with men who inject drugs (MSM-IDUs). In many parts of the world, injecting drug use also indirectly accounts for a sizable proportion of HIV cases spreading through sexual transmission from IDUs to non-injecting populations, and through perinatal transmission to newborns. Below, we highlight trends in the epidemiology of HIV infection among IDUs and the increasing role of non-IDUs in various HIV epidemics worldwide and in the United States.

\section{Global Trends in the Epidemiology of HIV Infection Among Drug Injectors}

In 2008, injecting drug use had been reported in 148 countries and territories, but prevalence of injecting drug use was available for fewer than half (i.e., 61 countries) [ $1 \bullet]$. Based on available data from these countries, country-level prevalence of injecting drug use ranges widely from $0.02 \%$ in India and Cambodia to Georgia with $4.19 \%$ and Azerbaijan with $5.21 \%[1 \bullet, 2]$. Since injecting drug use is more common in urban areas, country-level prevalence estimates can mask considerable within-country heterogeneity. 
Extrapolated estimates suggest that 15.9 million (range 11.0-21.1 million) people might inject drugs worldwide $[1 \bullet]$. China, the United States, the Russian Federation, and Brazil are estimated to have the largest populations of IDUs and together account for $45 \%$ of the total estimated worldwide population of IDUs. However, data for the extent of injecting drug use was absent for many countries in Africa, the Middle East, and Latin America [1•].

Injecting drug use is responsible for an increasing proportion of new HIV infections in many parts of the world, including countries in Eastern Europe, South America, and east and southeast Asia [1•]. HIV prevalence among IDUs was reported as zero in only eight $(5.4 \%)$ of 148 countries. In 2006, it was estimated that 3 million (range 1-7 million) IDUs may be living with HIV worldwide [1•]. In China, the United States, and Russia, the three leading countries for injecting drug use, the HIV prevalence among IDUs was $12 \%, 16 \%$, and $37 \%$, respectively (Fig. 1) [1•]. High HIV prevalence estimates were found in southeast Asia, Eastern Europe, and Latin America, where the prevalence of HIV infection among some subpopulations of people who inject drugs has been reported to be over $40 \%$. HIV prevalence among IDUs was $20-40 \%$ in five countries: Russia (37.2\%), Spain (39.7\%), Cambodia (22.8\%), Vietnam (33.9\%), and Libya (22.0\%). HIV prevalence was over $40 \%$ in nine countries: Estonia (72.1\%), Ukraine (41.8\%), Burma (42.6\%), Indonesia (42.5\%), Thailand (42.5\%), Nepal (41.4\%), Argentina (49.7\%), Brazil (48.0\%), and Kenya (42.9\%) [1•].

A few regional injecting drug use associated HIV epidemics deserve special mention. Ukraine is considered to be the most HIV-affected country in Europe and Central Asia, with an estimated 440,000 HIV-infected persons between the

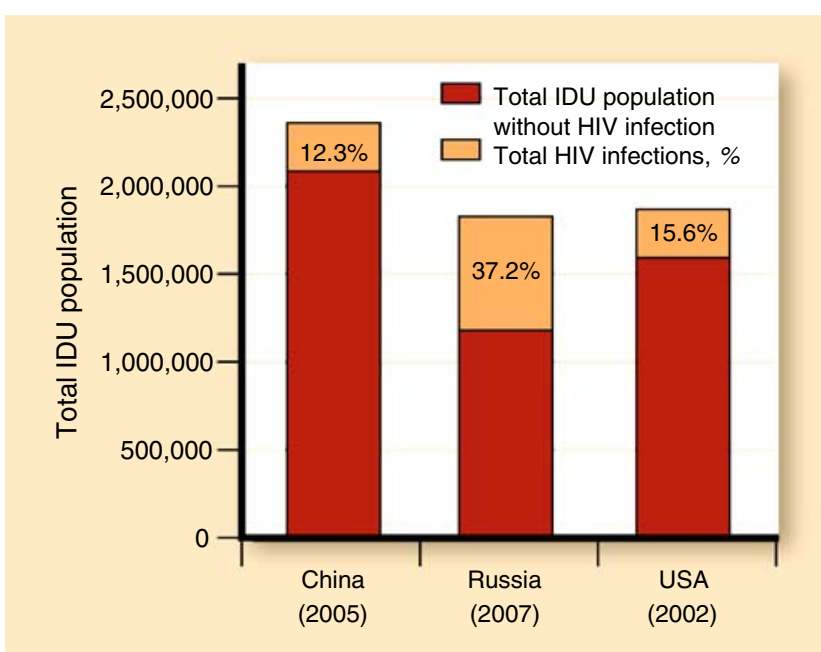

Fig. 1 Number and proportion of HIV infection among injecting drug users (IDUs) by the three leading countries for injecting drug use ages of 15 and 49 years (1.63\%) [3]. Ukraine's HIV epidemic began after the fall of the Iron Curtain, when changes in drug trafficking patterns, a faltering economy, and high unemployment rates led large numbers of young people to turn to injecting drugs, which were often home-made opiate preparations. In some cities, HIV prevalence among IDUs rose from nearly zero in 1994 to more than $50 \%$ within 2 years, and in the general population, HIV prevalence is $1-2 \%$. It is estimated that as many as 820,400 people will be infected by 2014 [4]. Nearby in the Russian Federation and in several former Soviet republics, HIV prevalence and incidence is also rising, such as in St. Petersburg, which has experienced an explosive HIV epidemic in recent years [5]. While Russia and the Ukraine have implemented needle exchange programs (NEPs), they have been adamantly opposed to opioid substitution therapies, especially in Russia where they remain illegal. In Ukraine, buprenorphine maintenance was introduced in recent years, although coverage remains less than 5\% [6].

There is growing concern about emerging epidemics of HIV among IDUs in several countries in sub-Saharan Africa against a backdrop of high HIV prevalence in the general population. At least in part, the burgeoning number of drug injectors is believed to be linked to the role that many African countries now play as trans-shipment routes in the global trafficking networks for heroin, cocaine, and other drugs [7]. Well-established HIV epidemics among IDUs exist in Nigeria, Kenya, Tanzania, South Africa, and Mauritius [1 $\bullet$. For example, by 2008 , injecting drug use accounted for $7 \%$ of incident HIV infections in Kenya [8], where the estimated HIV prevalence among IDUs is already $42 \%$ [1•]. In Dar E Salaam, Tanzania, where HIV prevalence among IDUs is also $42 \%$ [9], local practices such as "flashblood" (i.e., deliberately sharing of blood with drug preparations) may be fueling HIV transmission, but the extent to which this or similar practices exist elsewhere is unknown. Anecdotal evidence suggests that prisons may serve to potentiate HIV transmission due to the ample supply of drugs in the absence of sterile syringes [7]. To date, opioid substitution therapy (OST) has been implemented in only a few countries in subSaharan Africa, such as Mauritius, and some countries (e.g., Kenya) maintain laws prohibiting its use [10]. In addition, the high level of re-use of needles in medical establishments could potentiate HIV transmission, contributing further to generalized HIV epidemics [7].

Available data suggest that there may be 1,778,500 IDUs in sub-Saharan Africa (range: 534,500-3,022,500), among whom an estimated 221,000 (range: $26,000-572,000$ ) may be HIV-positive [1•]. However, since only 13 of 47 countries in sub-Saharan Africa have collected data on injecting drug use in their respective countries [1•], it is possible that injecting drug use, and the number of HIV infections among injectors, is even more widespread. The prevalence of drug injection across Africa is now estimated 
at $0.2 \%$ in the general population, a figure that is comparable to the United States [7].

\section{Features of the HIV Epidemic Among IDUs in the United States: Ethnic Disparities}

Since the late 1980 s, HIV incidence has declined by $80 \%$ among IDUs in the United States [11]. However, injecting drug use continues to account for a substantial proportion of new HIV diagnoses, especially considering the indirect role injecting drug use plays in heterosexual HIV transmission [12]. In 2007, injecting drug use was the third most frequently reported risk factor for HIV infection, after maleto-male sexual contact and high-risk heterosexual contact [12]. The most striking feature of the HIV epidemic among IDUs in the United States are the dramatic racial disparities. During 2004-2007, a total of 152,917 people were diagnosed with HIV infection in 34 US states, including 19,687 IDUs (12.9\%) [12]. The majority of HIV-infected IDUs were male (62.2\%) and aged 35-44 years (33.2\%). Blacks accounted for $57.5 \%$ of HIV-infected IDUs, whites for $21.4 \%$, Hispanics for $19.1 \%$, American Indians or Alaska Natives for $0.6 \%$, Asians for $0.4 \%$, and Native Hawaiians or Other Pacific Islanders for $0.1 \%$ [12].

The average annual rate of new HIV infection diagnosis per 100,000 general population during 2004-2007 was 11.0 for black IDUs, 4.9 per 100,000 for Hispanic IDUs, and 0.9 per 100,000 for white IDUs. Among these IDU subgroups, male blacks had the highest average annual rate of new HIV diagnosis per 100,000 general population (17.3), followed by female blacks (9.3), male Hispanics (7.0), and female Hispanics (2.7) [13].

Among male IDU HIV cases, whites and American Indian/Alaska natives had a higher proportion of HIV cases occurring among MSM-IDUs. Among American Indian communities, having a gay/bisexual identity is referred to as being "two-spirited." Among females, the distribution of injecting drug use related HIV/AIDS diagnoses was similar across whites, blacks, and Hispanics, but the proportion of HIV cases attributable to injecting drug use was lower among Asian/Pacific Islanders and higher among American Indians [13].

Important changes may be occurring in the epidemiologic landscape of HIV infection among IDUs in the United States, an epidemic that has up until now been so entrenched among communities of color. In a multicity study across the United States, Broz and Ouellet [14•] found a tendency for young black drug users to avoid injecting drug use in recent years, whereas there was no such trend among young whites. These data are supported by race-specific and age-specific trends in HIV cases collected by the US Centers for Disease Control and Prevention (Fig. 2). While the proportion of injecting drug use related HIV cases among whites surpassed blacks in the 20-24 age group and decreased with age [12], the proportion of injecting drug use related HIV cases among blacks generally increased with increasing age, and the proportion of IDU-related HIV cases among Hispanics was similar for all age groups [12]. Finally, among 13,519 IDUs recruited through respondent-driven sampling in a behavioral surveillance study from 2005 to 2006 in 23 US cities, the highest prevalence of needle sharing was reported among nonHispanic whites $(66 \%)$, followed by $56 \%$ among Hispanics and blacks [11]. Non-Hispanic whites were also less likely to have had a recent HIV test or to have been reached by an HIV intervention, compared with Blacks or Hispanics. Taken together, these provocative data suggest that the disproportionate burden of HIV cases among black IDUs could begin to shift over the next few decades.
Fig. 2 Proportion of reported HIV cases related to injecting drug use, by race/ethnicity and age group through 2007: 53 areas. Includes persons of unknown race or multiple races (Source: the US Centers for Disease Control and Prevention, Atlanta, GA.)

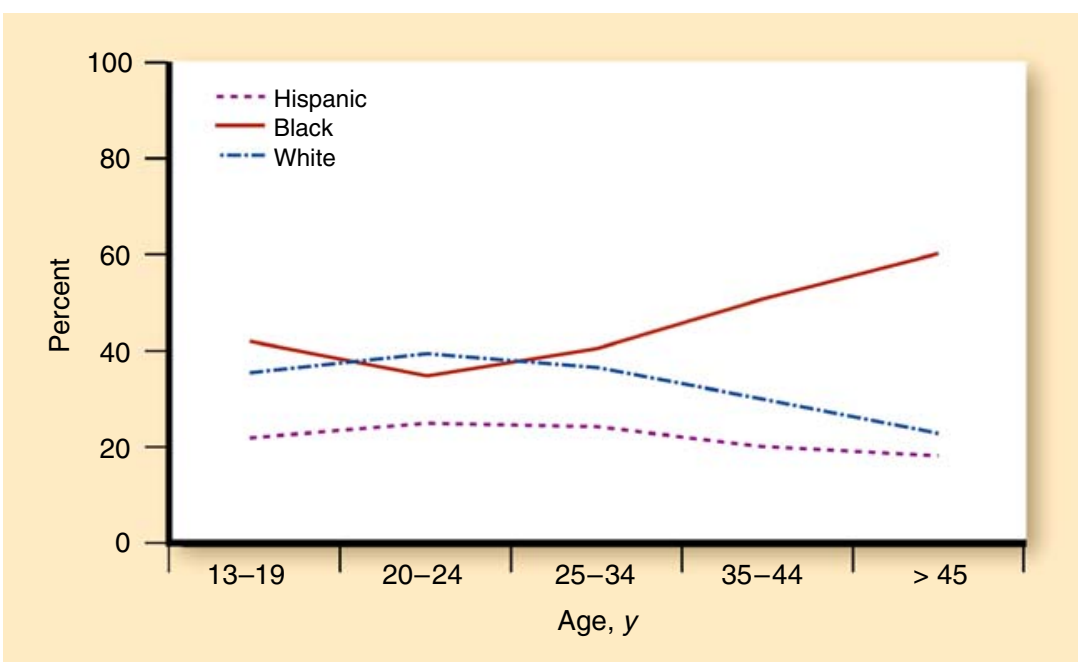




\section{Epidemiology of HIV Infection Among Non-injecting Drug Users}

The tendency for researchers and policymakers to focus attention on HIV among IDUs has tended to overshadow the extent to which individuals who use drugs by routes of administration other than injection (e.g., snorting, smoking) are affected by HIV. However, transmission from IDUs to non-IDUs and the general population is a growing concern in some regions with established injecting drug use related HIV epidemics [15-17]. In New York City [15], two separate cross-sectional surveys, at a detoxification and methadone maintenance treatment program from 2001 to $2004(n=2,121)$ and at a research storefront through respondent-driven sampling in 2004 ( $n=448)$, compared HIV prevalence among injecting and non-injecting heroin and cocaine users. In both studies, HIV prevalence was nearly identical: $13 \%$ among current injectors and $12 \%$ among non-IDUs from the drug treatment study, and 15\% among IDUs and 17\% among nonIDUs in the respondent-driven sampling storefront study.

In Baltimore, MD, 409 IDUs were compared with 165 nonIDUs, all of whom were aged 15-30 years and initiated use of cocaine, heroin, or crack within the previous 5 years [18]. Similar HIV prevalence was observed among IDUs and nonIDUs (4.4\% vs $3.6 \%)$. Elsewhere, HIV prevalence estimates are similar for non-IDUs and IDUs across countries, including Rio Grande do Sul, Brazil (11\% vs 13\%) [19] and Tijuana, Mexico (4\% vs 4\%) (Fig. 3) [20, 21].

Non-injecting drug use, or high-risk sexual behaviors associated with their use, may be an important factor contributing to HIV infection even among IDU populations. For example, in Yunnan, China, lifetime injecting and non- injecting drug use were both independently associated with HIV infection among female sex workers [22]. Among female sex workers in Tijuana and Ciudad Juarez, Mexico, injection of cocaine and snorting/smoking methamphetamine were both associated with HIV infection [23].

What are the possible mechanisms that explain higher HIV prevalence among non-IDUs compared to the general population in some settings? One of the most obvious explanations is a high degree of mixing or "bridging" between IDU and non-IDU populations, which can transmit HIV and other sexually transmitted infections through overlapping social and sexual networks. A clear example of this was reported in Manipur, India, where high HIV prevalence was observed among the wives of IDUs [16]. Similarly, bridging between IDUs and non-IDUs is hypothesized to explain diffusion and "interiorization" of HIV in Brazil [17]. Bridging of HIV between IDU and non-IDU populations can be expected to occur in outbreak situations where there is high HIV-1 viral load and even limited exposures can cause infection. Since there tends to be greater overlap between women's sexual and drug using networks compared to men's [24], and because male-tofemale HIV transmission is more efficient than female-tomale transmission, heterosexual females may be more likely to acquire HIV from their IDU sex partners than males. Unfortunately, this proportion remains unknown since HIV transmission categories do not capture the role of drug use apart from injection.

While sexual transmission bridges between IDUs and non-IDUs may help explain high HIV prevalence in some non-IDU populations, a second potential explanation for higher than average HIV prevalence among some non-IDU
Fig. 3 HIV prevalence among non-injecting and injecting drug users (IDUs), selected cities

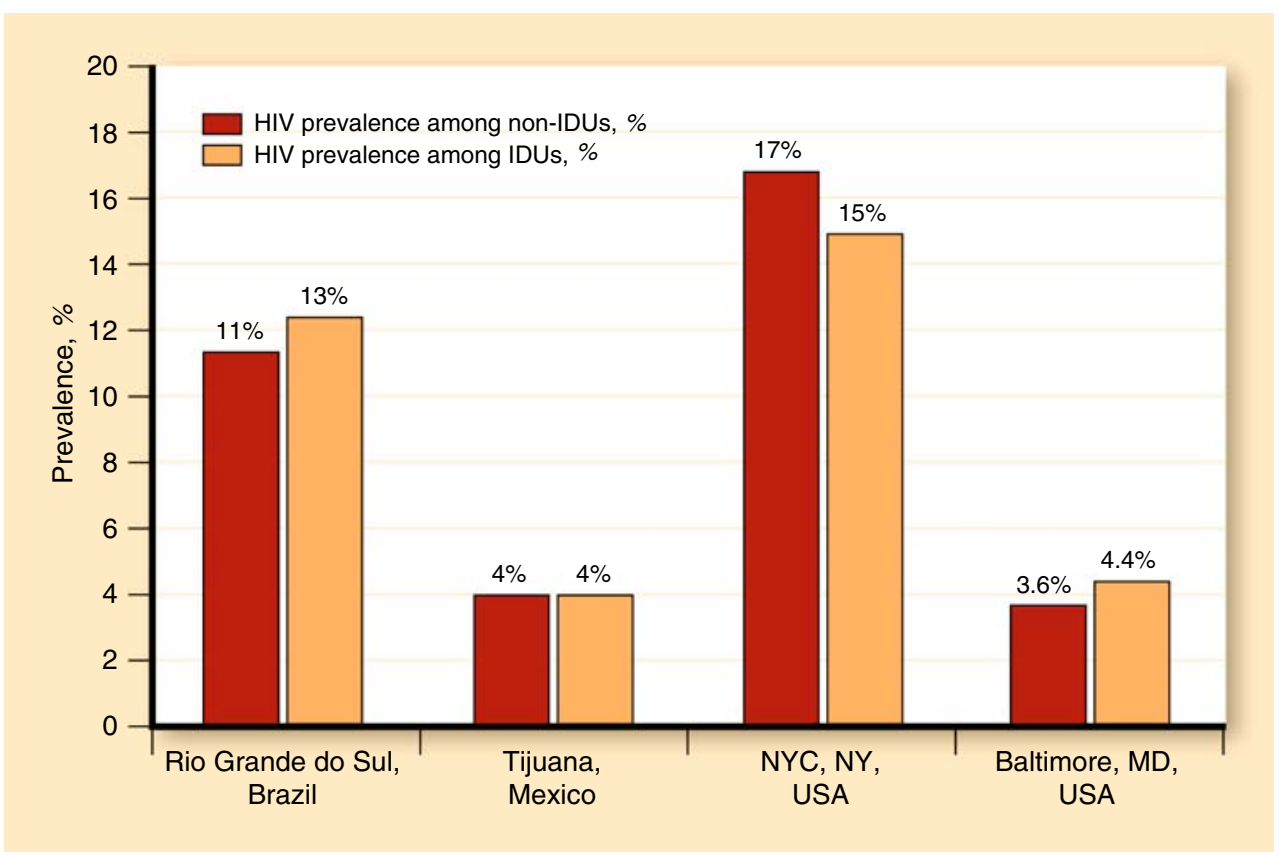


populations is that risky drug use behaviors among nonIDUs may represent true risk factors for HIV infection. In support of this argument, sharing of non-injection drug paraphernalia (i.e., straws, dollar bills used for snorting cocaine, inhalers, and pipes used to smoke crack) has been established as a risk factor for hepatitis $\mathrm{C}$ virus infection $[25,26]$, with the explanation being that drug users often have sores and cracks on their noses/mouths, which could facilitate viral transmission $[26,27]$. While these practices have been associated with HIV infection in some studies, an independent association between non-injecting drug use practices and HIV infection has yet to be reported after appropriate adjusting for injecting drug use and other known confounders. Additional studies are needed to disentangle these behaviors, perhaps using a combination of techniques such as molecular virology and social network analysis.

A third explanation for high HIV prevalence among nonIDU populations may be high levels of unprotected sex among non-IDUs, as is found among users of stimulants (i.e., crack, cocaine, methamphetamine). In contrast to persons who are dependent on heroin, stimulant users often engage in frequent high-risk behaviors with multiple sex partners. Context and circumstances vary, but the relationship between crack cocaine and the sex trade is well established [27-29], with some users trading sex for crack, rather than money, out of a desperate need to quell their withdrawal. Crack cocaine is now believed to be a major contributor to local HIV epidemics in Brazil and parts of the Caribbean (e.g., Bahamas, Puerto Rico, Dominican Republic, and Jamaica) [30]. Sex workers who are dependent on drugs may be less able to negotiate condom use due to inebriation, impaired judgment, or withdrawal, which may lead them to acquiesce to offers of unprotected sex for higher pay [31,32].

The growing use of methamphetamine and amphetaminelike stimulants may also play a role in HIV epidemics among non-IDU populations in various international settings. In a recent review [33], amphetamine or methamphetamine was documented in 110 countries, of which over half $(n=$ 60) reported the occurrence of methamphetamine injection. Injection of meth/amphetamine also appeared to be more common in countries reporting the crystalline form of the drug, which indicates the need for researchers to record drug formulation, as well as drug type. There was some evidence to suggest that its use was more prevalent in east and southeast Asia, North America, South Africa, New Zealand, Australia, and a number of European countries [33].

Certain populations of drug users appear to be higher consumers of methamphetamine, in particular, members of the gay/bisexual community who began using it as a party or "circuit club" drug in the 1990s. Methamphetamine use among MSM (including gay, bisexual, male-to-female transsexuals, and non-identifying MSM) in the United States, Australia, and western Europe ranges from 13\% to $39 \%$ [34, 35]. MSM who use methamphetamine often engage in high-risk behaviors such as high levels of unprotected sex, "marathon" sex, sex trading, and polydrug use, which includes both coadministration of other drugs at the same episode, and use of other drugs in different circumstances [36-38]. HIV incidence rates are double or triple for MSM who use amphetamines compared to nondrug using MSM, and may even be higher among MSM who inject methamphetamine and/or other drugs. A recent review found strong evidence that methamphetamine was causally associated with HIV infection, although there is insufficient evidence to conclude whether the causal pathway is direct, indirect, or both [38]. Methamphetamine use may also promote transmission of multidrug-resistant HIV $[39,40]$.

\section{Implications for Interventions}

The important role of injecting drug use in several regional HIV epidemics, and the tendency for HIV incidence to escalate rapidly once prevalence reaches a critical threshold, generally believed to be 5\% [41], underscores the need for rapid, simultaneous scale-up of effective interventions. It has been well established for at least a decade that NEPs can significantly reduce HIV prevalence and incidence among IDUs without incurring negative consequences in the community, and that OST can reduce the frequency of injecting drug use to such an extent that it can have a major impact in reducing HIV incidence at the community level $[42,43]$. Indeed, methadone and buprenorphine maintenance are included on the World Health Organization's Essential Drug List. Yet of the 148 countries where injecting drug use is known to occur, only $82(55 \%)$ were implementing NEPs and $70(47 \%)$ were implementing OST; both interventions are available in less than half (66 countries, or $44 \%$ ) [6]. OST is virtually absent in subSaharan Africa, with the exception of Mauritius, which introduced it recently.

The fact that less than one third of IDUs in the US Centers for Disease Control and Prevention's national behavioral surveillance program had been reached by an HIV intervention, and only $73 \%$ had ever been tested for hepatitis $\mathrm{C}$ virus [11], underscores the pressing need for programs that reach those at highest risk of infection, even in a resource-rich country such as the United States. Given that the US Congressional ban on federal funding for NEPs has finally been rescinded after more than two decades of moral opposition against these programs, it is fervently hoped that there will be a vigorous revitalization of publicly 
funded NEPs. Failure to do so will continue to undermine HIV prevention efforts at a national and international level, since some countries have delayed implementation of NEPs on the basis that the United States has been similarly delinquent. Empirical research has shown that NEPs are not only invaluable as a source of sterile syringes for disenfranchised drug injectors, but they are also important venues for offering ancillary services such as condom provision, drug treatment referrals, overdose prevention, $\mathrm{HIV} /$ sexually transmitted infection testing and counseling, tuberculosis screening and treatment, and hepatitis B virus vaccination $[42,44]$. Similarly, there is a parallel need for low-cost OST given that less than one fifth of drug users in the United States are receiving drug treatment at any given time [43].

In countries where HIV infection is already established, prevention programs need to extend beyond those that focus on injection and sexual risks, to ensure that when risky behaviors occur, the likelihood of HIV transmission is reduced. A recent study of IDUs in Vancouver, Canada suggests that appropriate coverage of HIV antiretroviral therapy (ART) at the community level can reduce HIV-1 viral load, and hence the risk of HIV infection [45]. Since it has also been shown that HIV-positive IDUs are just as likely to adhere to ART as non-IDUs [46], scaling up ART coverage should be considered a critical element of a comprehensive prevention package that includes widespread access to HIV testing and counseling, NEPs, and OST. A recent review of the international literature demonstrated that OST was significantly associated with greater ART adherence among IDUs, providing support for the integration of drug treatment and HIV treatment for drug-using populations [47]. There is a dire need to extend prevention programs to incarcerated populations, where high-risk injection and sexual behaviors are known to occur; to date, very few countries extend NEPs, OST, and ART to prisoners. Since several countries have shown that safer injection facilities are effective in reducing harms and encouraging IDUs to enter detoxification and OST [48], these programs are increasingly being recognized as an intervention worth including in the HIV prevention arsenal.

In regions where non-injecting drug use predominates as a risk factor for HIV infection, behavioral surveillance should be regularly conducted to monitor rates of transition from non-injecting to injecting drug use to enable the implementation of timely interventions. Since trends in drug use patterns are influenced by macro-level changes in drug trafficking routes, as well as drug availability, purity, price, and formulation, efforts to track changes in the global and regional drug markets may be helpful in forecasting their impact on local HIV epidemic trajectories. While prevention programs are clearly needed to prevent tran- sitions from non-injecting to injecting drug use, behavioral interventions are also needed to promote safer sex negotiation within the context of ongoing drug use. To date, a few theory-based interventions based on motivational interviewing have shown promise among HIV-positive MSM and HIV-negative heterosexuals who use methamphetamine $[49,50]$. Finally, safer inhalation rooms should be formally examined as an HIV prevention intervention for individuals who smoke or snort drugs such as crack cocaine, heroin, and methamphetamine, and have been implemented in a few European countries (e.g., Germany, Holland, Switzerland, and Spain). While these approaches may be controversial in some settings, empirically based scientific evidence-rather than the moral majority - should dictate which interventions are implemented as a prevention priority.

\section{Conclusions}

IDUs continue to bear a substantial burden of HIV globally, with high prevalence estimates in Eastern Europe, North Africa, the Middle East, North America, and many parts of Asia. In the United States, racial and ethnic disparities among IDUs are striking, with higher HIV incidence rates occurring among blacks and Hispanics compared to whites. Although significant attention has been given to describing the epidemiology of HIV among IDUs, the burden of HIV among non-IDUs is of growing importance due to their high-risk behaviors and overlapping social and sexual networks with IDUs. Efforts are needed to expand coverage of core interventions and to overcome moral opposition that has hampered the implementation of some interventions in regions that bear a disproportionate burden of HIV infections among drugusing populations.

Acknowledgments The authors would like to greatly acknowledge Monica Malta and Tom Patterson for their assistance in contributing data or interpretation of findings. The authors also acknowledge support from the National Institute of Health (NIH) grants R25 DA025571 and T32 DA023356 from the National Institute on Drug Abuse. The content is solely the responsibility of the authors and does not necessarily represent the official views of the National Institute of Drug Abuse or NIH.

Disclosure There are no possible conflicts of interest including financial support, corporate involvement, patent holdings, etc. for each author.

Open Access This article is distributed under the terms of the Creative Commons Attribution Noncommercial License which permits any noncommercial use, distribution, and reproduction in any medium, provided the original author(s) and source are credited. 


\section{References}

Papers of particular interest, published recently, have been highlighted as:

- Of importance

1. - Mathers BM, Degenhardt L, Phillips B, et al.: Global epidemiology of injecting drug use and HIV among people who inject drugs: A systematic review. Lancet 2008, 372:1733-1745. This is a global summary estimating the number of IDUs by country and region and the proportion who are HIV-positive among them.

2. United Nations Office on Drugs and Crime: World Drug Report. New York; 2009.

3. Ministry of Health of Ukraine: National report on monitoring progress towards the UNGLASS (United National General Assembly Special Session) declaration of commitment on HIV/ AIDS. Available at: http://www.unaids.org/en/CountryResponses/ Countries/ukraine.asp. Accessed February 2010.

4. World Bank/International HIV/AIDS Alliance in Ukraine: Socioeconomic Impact of HIV/AIDS in Ukraine. Washington, DC: Library of Congress; 2006.

5. Niccolai LM, Shcherbakova IS, Toussova OV, et al.: The potential for bridging of HIV transmission in the Russian Federation: sex risk behaviors and HIV prevalence among drug users (DUs) and their non-DU sex partners. J Urban Health 2009, 86(Suppl 1): 131-143.

6. Mathers B, Degenhardt L, Ali H, et al.: HIV prevention, treatment and care services for people who inject drugs: a systematic review of global, regional and country level coverage. Lancet 2010, 375:1014-1028.

7. Reid SR: Injection drug use, unsafe medical injections, and HIV in Africa: a systematic review. Harm Reduct J 2009, 6:24.

8. Gelmon L, Kenya P, Oguya F, et al.: Kenya HIV prevention response and modes of transmission (MOT) analysis. UNAIDS. Available at: http://www.unaidsrstesa.org/files/u1/Kenya MoT Country Synthe sis_Report_22Mar09.pdf. Accessed September 2009.

9. Williams ML, McCurdy SA, Bowen AM, et al.: HIV seroprevalence in a sample of Tanzanian intravenous drug users. AIDS Educ Prev 2009, 21:474-483.

10. Burris S, Corey SD: A blueprint for reforming access to opioid medications. Social Science Research Network. Available at: http://ssrn.com/abstract=1356815. Accessed September 2009.

11. Centers for Disease Control and Prevention (CDC): HIVassociated behaviors among injecting-drug users-23 Cities, United States, May 2005-February 2006. MMWR Morb Mortal Wkly Rep 2009, 58:329-332

12. Centers for Disease Control and Prevention (CDC): HIV infection among injection-drug users-34 states, 2004-2007. MMWR Morb Mortal Wkly Rep 2009, 58:1291-1295

13. Centers for Disease Control and Prevention: HIV/AIDS Surveillance in Injection Drug Users (through 2007). Available at: https://www. cdc.gov/hiv/idu/resources/index.htm. Accessed November 2009.

14. - Broz D, Ouellet LJ: Racial and ethnic changes in heroin injection in the United States: implications for the HIV/AIDS epidemic. Drug Alcohol Depend 2008, 94:221-233. This article describes the changing landscape of injection drug use patterns by ethnic group in the United States.

15. Des Jarlais DC, Arasteh K, Perlis T, et al.: Convergence of HIV seroprevalence among injecting and non-injecting drug users in New York City. AIDS 2007, 21:231-235

16. Panda S, Chatterjee A, Bhattacharya SK, et al.: Transmission of HIV from injecting drug users to their wives in India. Int J STD AIDS 2000, 11:468-473.
17. Hacker MA, Leite I, Friedman SR, et al.: Poverty, bridging between injecting drug users and the general population, and "interiorization" may explain the spread of HIV in southern Brazil. Health Place 2009, 15:514-519.

18. Strathdee SA, Sherman SG: The role of sexual transmission of HIV infection among injection and non-injection drug users. J Urban Health 2003, 80:iii7-iii14.

19. Bassols AM, Santos RA, Rohde LA, Pechansky F: Exposure to HIV in Brazilian adolescents: the impact of psychiatric symptomatology. Eur Child Adolesc Psychiatry 2007, 16:236242.

20. Strathdee SA, Lozada R, Ojeda VD, et al.: Differential effects of migration and deportation on HIV infection among male and female injection drug users in Tijuana, Mexico. PLoS One 2008, 3:e2690.

21. Deiss R: Prevalence and correlates of HIV infection among noninjection drug users in Tijuana, Mexico. Submitted 2010.

22. Wang H, Chen RY, Ding G, et al.: Prevalence and predictors of HIV infection among female sex workers in Kaiyuan City, Yunnan Province, China. Int J Infect Dis 2009, 13:162-169.

23. Patterson TL, Semple SJ, Staines H, et al.: Prevalence and correlates of HIV infection among female sex workers in 2 Mexico-US border cities. J Infect Dis 2008, 197:728-732.

24. Sherman SG, Latkin CA: Intimate relationship characteristics associated with condom use among drug users and their sex partners: a multilevel analysis. Drug Alcohol Depend 2001, 64:97-104.

25. Aaron S, McMahon JM, Milano D, et al.: Intranasal transmission of hepatitis $\mathrm{C}$ virus: virological and clinical evidence. Clin Infect Dis 2008, 47:931-934.

26. Tortu S, McMahon JM, Pouget ER, Hamid R: Sharing of noninjection drug-use implements as a risk factor for hepatitis C. Subst Use Misuse 2004, 39:211-224.

27. Edlin BR, Irwin KL, Faruque S, et al.: Intersecting epidemicscrack cocaine use and HIV infection among inner-city young adults. Multicenter Crack Cocaine and HIV Infection Study Team. N Engl J Med 1994, 331:1422-1427.

28. de Souza CT, Diaz T, Sutmoller F, Bastos FI: The association of socioeconomic status and use of crack/cocaine with unprotected anal sex in a cohort of men who have sex with men in Rio de Janeiro, Brazil. J Acquir Immune Defic Syndr 2002, 29:95-100.

29. Inciardi JA: Crack, crack house sex, and HIV risk. Arch Sex Behav 1995, 24:249-269.

30. Hacker MA, Malta M, Enriquez M, Bastos FI: Human immunodeficiency virus, AIDS, and drug consumption in South America and the Caribbean: epidemiological evidence and initiatives to curb the epidemic. Rev Panam Salud Publica 2005, 18:303-313.

31. Strathdee SA, Philbin MM, Semple SJ, et al.: Correlates of injection drug use among female sex workers in two Mexico-U.S. border cities. Drug Alcohol Depend 2008, 92:132-140.

32. Lau JT, Tsui HY, Zhang Y, et al.: Comparing HIV-related syringesharing behaviors among female IDU engaging versus not engaging in commercial sex. Drug Alcohol Depend 2008, 97:54-63.

33. Degenhardt L, Mathers B, Guarinieri M, et al.: Meth/amphetamine use and associated HIV: Implications for global policy and public health. Int J Drug Policy 2010, In press.

34. Shoptaw S, Reback CJ: Methamphetamine use and infectious disease-related behaviors in men who have sex with men: implications for interventions. Addiction 2007, 102(Suppl 1): $130-135$.

35. Rawstorne P, Digiusto E, Worth H, Zablotska I: Associations between crystal methamphetamine use and potentially unsafe sexual activity among gay men in Australia. Arch Sex Behav 2007, 36:646-654. 
36. Semple SJ, Zians J, Strathdee SA, Patterson TL: Sexual marathons and methamphetamine use among HIV-positive men who have sex with men. Arch Sex Behav 2009, 38:583-590.

37. Semple SJ, Strathdee SA, Zians J, Patterson TL: Sexual risk behavior associated with co-administration of methamphetamine and other drugs in a sample of HIV-positive men who have sex with men. Am J Addict 2009, 18:65-72.

38. Drumright LN, Patterson TL, Strathdee SA: Club drugs as causal risk factors for HIV acquisition among men who have sex with men: a review. Subst Use Misuse 2006, 41:1551-1601.

39. Toussi SS, Joseph A, Zheng JH, et al.: Short communication: Methamphetamine treatment increases in vitro and in vivo HIV replication. AIDS Res Hum Retroviruses 2009, 25:1117-1121.

40. Cachay ER, Moini N, Kosakovsky Pond SL, et al.: Active methamphetamine use is associated with transmitted drug resistance to non-nucleoside reverse transcriptase inhibitors in individuals with HIV infection of unknown duration. Open AIDS J 2007, 1:5-10

41. Friedman SR, Des Jarlais DC: HIV among drug injectors: the epidemic and the response. AIDS Care 1991, 3:239-250.

42. Vlahov D, Robertson AM, Strathdee SA: HIV prevention among injection drug users in resource-limited settings. Clin Infect Dis 2010, In press.

43. Metzger DS, Navaline H: HIV prevention among injection drug users: the need for integrated models. J Urban Health 2003, 80: iii59-iii66
44. Des Jarlais DC, McKnight C, Goldblatt C, Purchase D: Doing harm reduction better: syringe exchange in the United States. Addiction 2009, 104:1441-1446

45. Wood E, Kerr T, Marshall BD, et al.: Longitudinal community plasma HIV-1 RNA concentrations and incidence of HIV-1 among injecting drug users: prospective cohort study. BMJ 2009, 338: b1649.

46. Malta M, Magnanini MM, Strathdee SA, Bastos FI: Adherence to antiretroviral therapy among HIV-infected drug users: a metaanalysis. AIDS Behav 2008 Nov 20 (Epub ahead of print).

47. Malta M, Strathdee SA, Magnanini MM, Bastos FI: Adherence to antiretroviral therapy for human immunodeficiency virus/acquired immune deficiency syndrome among drug users: a systematic review. Addiction 2008, 103:1242-1257.

48. Kerr T, Kimber J, Debeck K, Wood E: The role of safer injection facilities in the response to HIV/AIDS among injection drug users. Curr HIV/AIDS Rep 2007, 4:158-164.

49. Mausbach BT, Semple SJ, Strathdee SA, et al.: Efficacy of a behavioral intervention for increasing safer sex behaviors in HIVnegative, heterosexual methamphetamine users: results from the Fast-Lane Study. Ann Behav Med 2007, 34:263-274.

50. Mausbach BT, Semple SJ, Strathdee SA, et al.: Efficacy of a behavioral intervention for increasing safer sex behaviors in HIVpositive MSM methamphetamine users: results from the EDGE study. Drug Alcohol Depend 2007, 87:249-257. 